\title{
Language barrier and its relationship to diabetes and diabetic retinopathy
}

\author{
Yingfeng Zheng ${ }^{1,2}$, Ecosse L Lamoureux ${ }^{1,3}$, Pei-Chia Peggy Chiang ${ }^{1}$, Ainur Rahman Anuar ${ }^{1,4,5}$, Jie Ding ${ }^{1}$, \\ Jie Jin Wang ${ }^{3,6}$, Paul Mitchell ${ }^{6}$, E-Shyong Tai ${ }^{8}$ and Tien Y Wong ${ }^{1,3,7^{*}}$
}

\begin{abstract}
Background: Language barrier is an important determinant of health care access and health. We examined the associations of English proficiency with type-2 diabetes (T2DM) and diabetic retinopathy (DR) in Asian Indians living in Singapore, an urban city where English is the predominant language of communication.

Methods: This was a population-based, cross-sectional study. T2DM was defined as HbA1c $\geq 6.5 \%$, use of diabetic medication or a physician diagnosis of diabetes. Retinal photographs were graded for the severity of DR including vision-threatening DR (VTDR). Presenting visual impairment (VI) was defined as LogMAR visual acuity $>0.30$ in the better-seeing eye. English proficiency at the time of interview was assessed.

Results: The analyses included 2,289 (72.1\%) English-speaking and 885 (27.9\%) Tamil- speaking Indians. Tamil-speaking Indians had significantly higher prevalence of T2DM (46.2 vs. $34.7 \%, p<0.001)$ and, among those with diabetes, higher prevalence of DR (36.0 vs. 30.6\%, p<0.001), VTDR (11.0 vs. 6.5\%, $p<0.001)$, and VI (32.4 vs. 14.6\%) than English speaking Indians. Oaxaca decomposition analyses showed that the language-related discrepancies (defined as the difference in prevalence between persons speaking different languages) in T2DM, DR, and VTDR could not be fully explained by socioeconomic measures.

Conclusions: In an English dominant society, Tamil-speaking Indians are more likely to have T2DM and diabetic retinopathy. Social policies and health interventions that address language-related health disparities may help reduce the public health impact of T2DM in societies with heterogeneous populations.
\end{abstract}

Keywords: English proficiency, Asian indians, Diabetes, Diabetic retinopathy, Visual impairment

\section{Background}

Type 2 diabetes (T2DM) is one of the leading causes of mortality and disability worldwide [1]. People with T2DM have a substantial risk of diabetic retinopathy (DR), which, if left untreated, can lead to vision-threatening diabetic retinopathy (VTDR) and ultimately to visual impairment (VI) [2]. Recent evidence suggests that T2DM and its complications are not only determined by biological and lifestyle risk factors (e.g., obesity, hypertension, physical inactivity and unbalanced diet) [1], they are also affected by a broad range of social determinants (e.g., socioeconomic status and social support) [3].

\footnotetext{
* Correspondence: ophwty@nus.edu.sg

${ }^{1}$ Singapore Eye Research Institute, Singapore National Eye Centre, 11 Third Hospital Ave, \#05-00, Singapore 168751, Singapore

${ }^{3}$ Centre for Eye Research Australia, University of Melbourne, the Royal

Victorian Eye and Ear Hospital, 32 Gisborne Street, East Melbourne, VIC 3002,

Australia

Full list of author information is available at the end of the article
}

Language barrier, among other social determinants, is known as an important factor predicting poorer health and barrier to care [4-10]. However, the impact of language barrier on diabetes and its ocular consequences have not previously been documented. Language barrier can be easily measured by a participant's English proficiency during survey interview [11,12]. English proficiency during the interview is a functional measure determined by interviewers and therefore it is not subject to self-assessment bias [10,11].

Asian Indians are among the fastest growing ethnic groups in the United States, the United Kingdom, and in many Asian countries including Singapore. In Singapore, ethnic Indians $(9.2 \%)$ is the nation's third largest ethnic group, behind ethnic Chinese (74.1\%) and Malays (13.4\%) $[13,14]$. There are four major spoken languages (English, Mandarin, Malay and Tamil) in Singapore, with English being the official language for business, education and
C Biomed Central

(c) 2012 Zheng et al.; licensee BioMed Central Ltd. This is an Open Access article distributed under the terms of the Creative Commons Attribution License (http://creativecommons.org/licenses/by/2.0), which permits unrestricted use, distribution, and reproduction in any medium, provided the original work is properly cited. 
politics. However, more than $36 \%$ of Singaporean Indians reported Tamil as the language spoken most often at home [15]. The impacts of language skill on disease status has never been evaluated in Singapore, where the prevalence of diabetes was reported to be as high as $21.8 \%$ among those aged 50-59 and 32.4\% among those aged 60 and over, and it disproportionately affects ethnic Indians more than any other $[13,14]$. Given the high prevalence of diabetes among Asian Indians and the unique multilingual nature of the country, we aimed to examine language-related disparities (defined as the difference in prevalence between persons normally speaking English and those normally speaking Tamil) in the prevalence of T2DM, DR and VI. Furthermore, if the effect of language is substantial, understanding why disparities exist between English and non-English speakers and the extent to which the language-related variation in health is due to variation in individual-level variables (e.g., biological risk factors, education, and income) may provide insights into public health strategies to reduce the burden and impact of T2DM. To answer this question, we used an Oaxaca decomposition method to decompose language-related disparities in the prevalence of T2DM, DR, VTDR and VI, and to quantify the contribution of individual-level variables.

\section{Methods}

\section{Study population}

The Singapore Indian Eye Study is a population-based cross-sectional study of Singaporean Indians aged 40 and over. Details of its methodology have been reported previously [16,17]. The Ministry of Home Affairs provided initial computer-generated lists of persons of Indian ethnicity residing in south-west Singapore. Of the 4,497 eligible subjects from the sampling frame, 3,400 (75.6\%) participated. The study adhered to the Declaration of Helsinki and ethics approvals were obtained from the Singapore Eye Research Institute Institutional Review Board.

\section{Diabetes and diabetic retinopathy assessment}

Based on American Diabetes Association's diagnostic criteria, diabetes was defined as a self-reported previous diagnosis of the disease, or a hemoglobin A1c (Hba1c) $\geq$ $6.5 \%$. A participant was considered to have type-1 diabetes if younger than 30 years when diagnosed with diabetes and received insulin therapy from diagnosis; other participants were considered to have T2DM.

Retinal photography was performed using a standardized protocol. After pupil dilation, one retinal photograph centered on the optic disc and another one on the macula were taken from both eyes using a digital retinal camera (Canon CR-DGi with a 10-D SLR back; Canon,
Tokyo, Japan). Photographs were then sent to the University of Sydney, and retinopathy lesions were graded according to a scale modified from the Airlie House classification system [18,19]. Retinopathy severity was categorized into minimal non-proliferative diabetic retinopathy (NPDR; levels 15 and 20), mild NPDR (level 35), moderate NPDR (levels 43 and 47), severe NPDR (level 53), and proliferative diabetic retinopathy (PDR, levels more than 60). Diabetic macular edema was defined by a finding of hard exudates in the presence of MA and blot hemorrhage with one disc diameter from the foveal center or the presence of focal photocoagulation scars at the macular area. Those with diabetic macular edema were further divided into cases with clinically significant macular edema (CSME) and without CSME. CSME was defined by macular edema within $550 \mu \mathrm{m}$ of the foveal center or if focal photocoagulation scars were present in the macular area. VTDR was defined as the presence of severe NPDR, PDR, or CSME. The severity scores of the worse of the two eyes were used for the individual. If the images in one eye were ungradable, the scores for the fellow eye were used to define these outcomes.

Visual acuity was measured using a logarithm of the minimum angle of resolution (logMAR) number chart (Lighthouse International, New York, NY). Presenting VI was defined as VA worse than 20/40 (logMAR > 0.30) in the better-seeing eye. Body Mass Index (BMI) was defined as weight divided by the square of height in meters $(\mathrm{kg} / \mathrm{m} 2)$. Systolic blood pressure (SBP) and diastolic blood pressure (DBP) were measured using a digital automatic blood pressure monitor (Dinamap model Pro100V2; Criticon GmbH, Norderstedt, Germany). Nonfasting venous blood samples were drawn and sent for biochemistry tests, including analysis of total cholesterol, high density lipoprotein cholesterol (HDL), low density lipoprotein (LDL) cholesterol, triglycerides, glucose, and HbA1c.

\section{English proficiency and other questionnaire-based measurements}

A detailed interviewer-administered questionnaire was used to collect questions on demographics, acculturation, socioeconomic measures and reading literacy. The questionnaire was administered in three languages, including English, Tamil and Malay. English questionnaires were translated into the other two languages using a standard "forward-backward" translation procedure. Multilingual interviewers made the first contact with the participants and asked about participants' language proficiency and preference for interview, and assigned those who preferred speaking Tamil or Malay and those who experienced difficulties in speaking 
English to the interviewers who were fluent in Tamil or Malay. The Malay-speaking sample was not included in this study, because of the relative smaller sample size $(n=226)$ and therefore limited statistical power.

Other collected information included age, sex, smoking history $(0=$ past or never; $1=$ current $)$, education $(0=$ secondary education or higher; 1 =primary education or lower $)$, income $(0=$ earning $>$ Singapore dollar [SGD] 1,000 per month; $1=$ earning $<$ SGD 1,000), current housing status $(0=5$ room flat/private house; $1=3-4$ room flat or less), self-reported reading literacy $(0=$ adequate; 1 = inadequate) [20] and acculturation factors including length of residence in Singapore and country of birth ( 0 = Singapore-born; 1 = foreign-born).

\section{Statistical analysis}

\section{Logistic regression estimates}

We developed univariate and multivariate logistic regression models to examine the associations between potential risk factors (e.g., age, sex, blood pressure, BMI, English proficiency, length of residence in Singapore, country of birth, literacy, and socioeconomic measures) and the presence of T2DM, DR, VTDR, or VI. Statistical analyses were performed using STATA software (Version 8.2, Stata Corp., College Station, TX). Interaction terms between English proficiency and socioeconomic measures were constructed and heterogeneity was tested with the Wald test; the significant term would be included in multivariate models.

\section{Oaxaca decomposition}

We used an Oaxaca decomposition method to decompose the differences in the prevalence of T2DM, DR, VTDR, and VI between the Tamil-speaking and English-speaking Indians. Oaxaca decomposition method is designed to decompose differences between in an outcome of interest into portions attributable to differences in the distributions of endowments (explanatory variables) and differences in returns to these endowments (coefficients) [21]. For example, this method has been widely in the labor market to examine whether the wage differences could be decomposed into characteristics ("explained") and discriminations components ("unexplained"). Statistically, it allows us to decompose the difference between groups into two parts: Q and U. Q is the part of the outcome differential that is attributed to group differences in the covariates (e.g., the proportion of difference in prevalence of T2DM that can be explained by different levels of blood pressure in the two groups), and $U$ is the part of the outcome differential that is attributed to discrimination or effects of differences in unobserved variables. The simple linear regression model can be expressed as:

$$
Y_{\ell}=X_{\ell}^{\prime} \beta_{\ell}+\epsilon_{\ell}, \quad E\left(\epsilon_{\ell}\right)-0, \quad \ell \in\{A, B\}
$$

Where $\mathrm{Y}$ is the outcome variable; $\beta$ is the coefficient and $>$ is the error.

In the standard Blinder-Oaxaca decomposition, given group A (Tamil-speaking group) and group B (Englishspeaking group), the mean outcome difference $\mathrm{R}$ can be decomposed as:

$$
R=E\left(Y_{A}\right)-E\left(Y_{B}\right)=E\left(X_{A}\right)^{\prime} \beta_{A}-E\left(X_{B}\right)^{\prime} \beta_{B}
$$

Where $\beta^{*}$ is a flexible coefficient depends on the

$$
\begin{array}{r}
\mathrm{R}=\left[E\left(X_{A}\right)-E\left(X_{B}\right)\right] \beta *+\left[E\left(X_{A}\right)^{\prime}\left(\beta_{A}-\beta *\right)^{\prime}+E\left(X_{B}\right)^{\prime}\left(\beta *-\beta_{B}\right)\right] \\
\text { "explained"part }(Q) \quad \text { "unexplained"part }(U)
\end{array}
$$

choice of reference group. We followed Neumark's method where $\beta^{*}$ was derived from the pooled regression over both groups [22]. Since Y is a binary outcome (yes or no), we followed Fairlie's method by setting $(\beta)$ in Oaxaca logistic decomposition model [23].

\section{Results}

Table 1 shows the baseline characteristics of the 3,174 participants, stratified by their English proficiency. Compared with the English-speaking participants, Tamilspeaking participants were more likely to be older, female, non-smoker and born outside Singapore; and they had higher levels of BMI, HbA1c and SBP, and lower levels of DBP, socioeconomic status and literacy (all $P<0.05)$. Tamil-speaking Indians were more likely to have T2DM (raw prevalence: $46.2 \%$ versus $34.7 \%$ ) and, among those with diabetes, DR (raw prevalence: $36.0 \%$ versus 30.6\%), VTDR (raw prevalence: $11.0 \%$ versus $6.5 \%$ ) and VI (raw prevalence: $32.4 \%$ versus 14.6\%), compared with English-speaking Indians. Figure 1 shows the age-standardized prevalence of DR stratified by English proficiency and Figure 2 shows the age-standardized prevalence of VI.

In traditional logistic regression model, after controlling for important covariates and risk factors, Tamilspeaking Indians were still significantly more likely to have T2DM (OR $=1.25$; 95\% CI: 1.04 to 1.52$)$; and among those with diabetes, $\mathrm{DR}(\mathrm{OR}=1.20 ; 95 \% \mathrm{CI}: 1.05$ to 1.70), VTDR (OR $=1.70 ; 95 \% \mathrm{CI}: 1.06$ to 3.01$)$ and VI $(\mathrm{OR}=1.56$; $95 \% \mathrm{CI}: 1.03$ to 2.34$)$ compared to Englishspeaking Indians. There was no significant interaction between English proficiency and socioeconomic measures ( $P$ for interaction $>0.05$, data not shown) and between English-proficiency and age $(P=0.42)$. We also carried out stratified analyses by examining the 
Table 1 Sociodemographic and Clinical Characteristics of the Participants in the Singapore Indian Eye Study

\begin{tabular}{|c|c|c|c|c|}
\hline & \multirow[b]{2}{*}{ All participants $(n=3174)$} & \multicolumn{2}{|l|}{ English proficiency } & \multirow[t]{2}{*}{ P value* } \\
\hline & & English-speaking $(n=2289)$ & Tamil-speaking $(n=885)$ & \\
\hline \multicolumn{5}{|l|}{ Age groups } \\
\hline 40-49 years & $866(27.3)$ & $750(32.8)$ & $116(13.1)$ & \\
\hline $50-59$ years & $1036(32.6)$ & $818(35.7)$ & $218(24.6)$ & \\
\hline $60-69$ years & $820(25.8)$ & $528(23.1)$ & $292(33.0)$ & \\
\hline $70-80$ years & $452(14.2)$ & $193(8.4)$ & $259(29.3)$ & $<0.001$ \\
\hline Gender (male) & $1612(50.8)$ & $1300(56.8)$ & $312(35.3)$ & $<0.001$ \\
\hline BMI $\left(\mathrm{kg} / \mathrm{m}^{2}\right)$ & $26.1(4.7)$ & $26.0(4.4)$ & $26.4(5.4)$ & $<0.001$ \\
\hline HbA1c (\%) & $6.4(1.4)$ & $6.4(1.4)$ & $6.6(1.4)$ & 0.002 \\
\hline SBP $(\mathrm{mmHg})$ & $134.9(19.6)$ & $132.9(18.6)$ & $140.2(20.9)$ & $<0.001$ \\
\hline $\mathrm{DBP}(\mathrm{mmHg})$ & $77.4(10.1)$ & $77.8(10.1)$ & $76.4(10.1)$ & 0.003 \\
\hline Total cholesterol (mmol/l) & $5.2(1.1)$ & $5.2(1.1)$ & $5.1(1.1)$ & $<0.001$ \\
\hline HDL cholesterol (mmol/l) & $1.07(0.32)$ & $1.10(0.32)$ & $1.12(0.31)$ & $<0.001$ \\
\hline LDL cholesterol (mmol/l) & $3.33(0.94)$ & $3.36(0.94)$ & $3.23(0.92)$ & 0.003 \\
\hline Triglycerides (mmol/l) & $1.96(1.16)$ & $2.01(1.23)$ & $1.83(0.94)$ & $<0.001$ \\
\hline Current smoking (yes) & $462(14.6)$ & $369(16.1)$ & $93(10.5)$ & $<0.001$ \\
\hline \multicolumn{5}{|l|}{ Country of birth } \\
\hline Foreign-born & $1280(40.3)$ & $784(34.3)$ & $496(56.0)$ & \\
\hline Singapore-born & $1894(59.7)$ & $1505(65.8)$ & $389(44.0)$ & $<0.001$ \\
\hline \multicolumn{5}{|l|}{ Literacy level } \\
\hline Adequate reading literacy & $2941(92.7)$ & $2211(96.6)$ & $730(82.5)$ & \\
\hline Inadequate reading literacy & $233(7.3)$ & $78(3.4)$ & $155(17.5)$ & 0.001 \\
\hline \multicolumn{5}{|l|}{ Education level } \\
\hline Primary education or lower & $1688(53.3)$ & $934(40.9)$ & $754(85.2)$ & \\
\hline Secondary education or higher & $1482(46.7)$ & $1351(59.1)$ & $131(14.8)$ & $<0.001$ \\
\hline \multicolumn{5}{|l|}{ Income level } \\
\hline$<S \$ 1000$ & $1538(48.5)$ & $881(38.5)$ & $657(74.2)$ & \\
\hline$\geq \$ \$ 1000$ & $1636(51.5)$ & $1408(61.5)$ & $228(25.8)$ & $<0.001$ \\
\hline \multicolumn{5}{|l|}{ Housing type } \\
\hline 3-4 room flat or smaller & $1996(63.0)$ & $1288(56.3)$ & $708(80.0)$ & \\
\hline 5 room flat/private & $1175(37.0)$ & $998(43.7)$ & $177(20.0)$ & $<0.001$ \\
\hline
\end{tabular}

Data presented are means (standard deviations) or number (\%), as appropriate for variable. $\mathrm{BMI}=$ Body mass index; $\mathrm{HbA} 1 \mathrm{C}=$ hemoglobin $\mathrm{A} 1 \mathrm{C} ; \mathrm{SBP}=$ systolic blood pressure; $\mathrm{DBP}=$ diastolic blood pressure; $\mathrm{HDL}=$ high-density lipoprotein; $\mathrm{LDL}=$ low-density lipoprotein; $\mathrm{S}=$ Singapore dollar.

*P value, comparing the differences between English- and Tamil-speaking Indians, based on analysis of variance or chi-square test, as appropriate.

associations of English proficiency (Tamil versus English) with T2DM, DR, VTDR, and VI, stratified by country of birth, education or income. The relationships between English proficiency and T2DM were slightly strengthened among the Singapore-born Indians, those with secondary education level or higher, and those with an income level $<S \$ 1000$ (all with $P<0.001$ ). The relationships of English proficiency with DR, VTDR and VI were slightly strengthened among the Singapore-born Indians, those with primary education level or less, and those with an income level $\geq S \$ 1000$ (all with $P<0.001$ ).
Table 2 shows the findings of our Oaxaca decomposition analyses for T2DM, DR, VTDR and VI. Tamilspeaking Indians had a higher prevalence of T2DM than English-speaking Indians, by 11.6 percentage points. In the analyses stratified by age groups, Tamil-speaking Indians consistently had a higher prevalence of T2DM (data not shown), Two thirds of the difference (8.4/11.6) was attributed to the differences in the groups' individual characteristics ("explained" component) and the rest could not be explained by the difference in individual characteristics ("unexplained" component). Age had the biggest contribution to the "explained" component: if age 


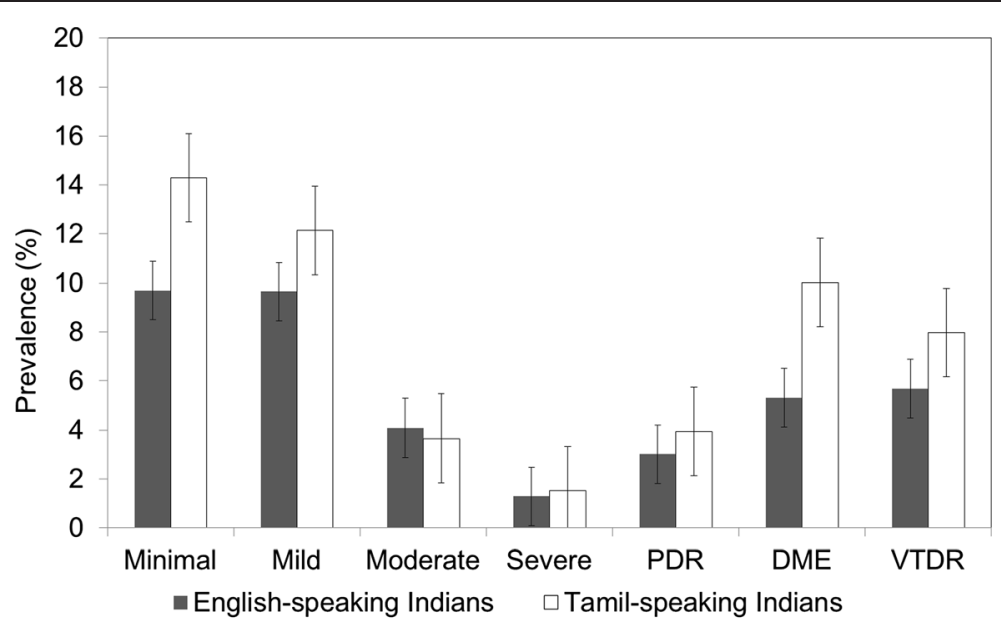

Figure 1 Proportion of Diabetic Retinopathy Stratified by English Proficiency. PDR= proliferative diabetic retinopathy; VTDR = visionthreatening diabetic retinopathy.

distributions in the two groups were similar, the difference in prevalence of T2DM would have been predicted to reduce by 3.4 percentage points. By contrast, if gender distributions in the two groups were similar, the difference in prevalence would have been predicted to even increase by 1.9 percentage points.

Among the patients with T2DM, Tamil-speaking Indians were more likely to have DR (by 6.1 percentage points) and VTDR (by 4.9 percentage points) than English-speaking Indians (Table 2). 50.8\% (3.1/6.1) of the difference in DR prevalence and $24.5 \%(1.2 / 4.9)$ of the difference in VTDR were attributed to the differences in the groups' individual characteristics ("explained" component) and the rest could not be explained by the difference in individual characteristics ("unexplained" component). Duration of diabetes and socioeconomic status (including income and housing type) had substantial contribution to the "explained" component for both DR and VTDR prevalence.

Among the patients with T2DM, Tamil-speaking Indians were twice as likely as English-speaking Indians to have VI, giving a gap of 17.0 percentage points (Table 2). Around $50 \%$ (8.3/17.0) this difference was attributed to the differences in the groups' individual

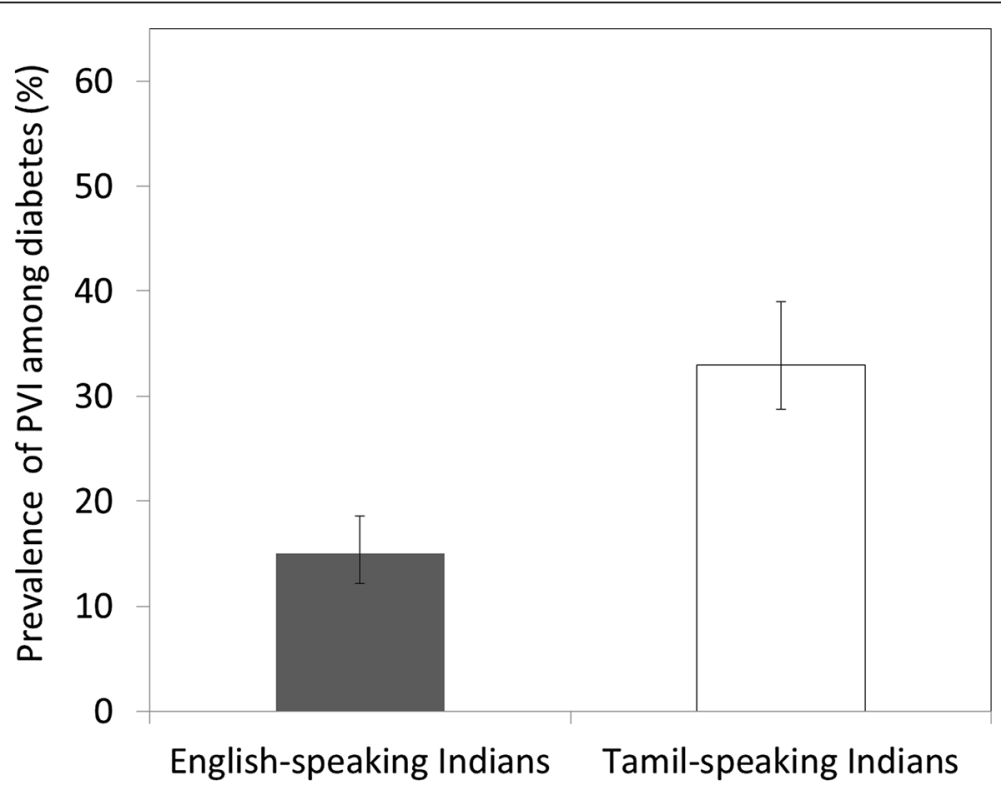

Figure 2 Proportion of Presenting Visual Impairment (PVI) Stratified by English Proficiency. 
Table 2 Oaxaca Multivariate Decomposition of Language-related Disparities in the Presence of Type-2 Diabetes and Its Ocular Complications

\begin{tabular}{|c|c|c|c|c|}
\hline & $\begin{array}{l}\text { Presence of Type-2 } \\
\text { Diabetes }\end{array}$ & $\begin{array}{l}\text { Presence of DR among } \\
\text { those with diabetes }\end{array}$ & $\begin{array}{l}\text { Presence of VTDR among } \\
\text { those with diabetes }\end{array}$ & $\begin{array}{l}\text { Presence of VI among } \\
\text { those with diabetes }\end{array}$ \\
\hline & Prediction $(95 \% \mathrm{Cl})$ & Prediction $(95 \% \mathrm{Cl})$ & Prediction $(95 \% \mathrm{Cl})$ & Prediction $(95 \% \mathrm{Cl})$ \\
\hline $\begin{array}{l}\text { Prevalence in } \\
\text { English-speaking Indians }\end{array}$ & $35.0 \%$ (33.0 to $36.9 \%)$ & $30.1 \%$ (26.8 to $33.3 \%)$ & $6.3 \%$ (4.6 to $8.0 \%)$ & $16.7 \%(14.1$ to $19.4 \%)$ \\
\hline $\begin{array}{l}\text { Prevalence in } \\
\text { Tamil-speaking Indians }\end{array}$ & $46.5 \%$ ( 43.2 to $49.9 \%)$ & $36.1 \%$ (31.3 to $41.0 \%)$ & $11.1 \%(8.1$ to $14.2 \%)$ & $33.7 \%$ ( 28.8 to $38.4 \%$ ) \\
\hline Difference & $-11.6 \%(-15.5$ to $-7.6 \%)$ & $-6.1 \%(-11.9$ to $-0.3 \%)$ & $-4.9 \%(-8.4$ to $-1.3 \%)$ & $-17.0 \%$ ( -22.4 to $-11.4 \%$ \\
\hline Explained & $-8.4 \%(-11.3$ to $-5.7 \%)$ & $-3.1 \%(-7.1$ to $-1.0 \%)$ & $-1.2 \%(-3.3$ to $-0.9 \%)$ & $-8.3 \%(-12.2$ to $-5.1 \%)$ \\
\hline Unexplained & $-3.2 \%(-7.7$ to $-1.4 \%)$ & $-3.0 \%(-9.2$ to $-3.2 \%)$ & $-3.7 \%(-7.5$ to $-0.2 \%)$ & $-8.7 \%(-14.7$ to $-1.8 \%)$ \\
\hline
\end{tabular}

Contribution of separate factors in explaining the explained proportion

Demographic factors

$\begin{array}{lllll}\text { Age (year) } & -\mathbf{3 . 4} \%(-\mathbf{5 . 1} \text { to }-\mathbf{1 . 6} \%) & \mathbf{7 . 3} \%(\mathbf{2 . 2} \text { to } \mathbf{1 2 . 3} \%) & \mathbf{2 . 6 \%}(\mathbf{0 . 0 6} \text { to } \mathbf{5 . 3} \%) & \mathbf{- 4 . 0 \% ( - 6 . 9} \text { to }-\mathbf{0 . 9} \%) \\ \text { Gender } & \mathbf{1 . 9} \%(\mathbf{0 . 9} \text { to } \mathbf{2 . 9} \%) & \mathbf{3 . 7} \%(\mathbf{1 . 0} \text { to } \mathbf{6 . 3} \%) & 0.9 \%(-0.3 \text { to } 2.1 \%) & 1.2 \%(-1.2 \text { to } 3.0 \%)\end{array}$

Systemic biological factors

\begin{tabular}{|c|c|c|c|c|}
\hline BMI $\left(\mathrm{kg} / \mathrm{m}^{2}\right)$ & $-0.6 \%(-1.2$ to $0.03 \%)$ & $0.01 \%(-0.3$ to $0.4 \%)$ & $0.01 \%(-0.1$ to $0.1 \%)$ & $0.01 \%(-0.2$ to $0.2 \%)$ \\
\hline SBP $(\mathrm{mmHg})$ & $-3.5 \%(-4.7$ to $-2.2 \%)$ & $-3.1 \%(-5.1$ to $-1.1 \%)$ & $-0.6 \%(-1.4$ to $0.1 \%)$ & $-0.2 \%(-0.7$ to $1.3 \%)$ \\
\hline $\mathrm{DBP}(\mathrm{mmHg})$ & $-0.8 \%$ ( -1.4 to $-0.2 \%)$ & $-1.5 \%(-2.8$ to $-0.2 \%)$ & $-0.5 \%(-1.1$ to $0.1 \%)$ & $-0.5 \%(-1.1$ to $0.4 \%)$ \\
\hline $\mathrm{HDL}(\mathrm{mmol} / \mathrm{l})$ & $0.3 \%(-0.02$ to $0.6 \%)$ & $-0.6 \%(-1.4$ to $0.2 \%)$ & $-0.1 \%(-0.5$ to $0.2 \%)$ & $-0.6 \%(-1.2$ to $0.1 \%)$ \\
\hline LDL (mmol/l) & $-1.4 \%(-2.2$ to $-0.6 \%)$ & $-0.4 \%(-1.0$ to $0.2 \%)$ & $0.1 \%(-0.2$ to $0.2 \%)$ & $0.3 \%(-0.2$ to $0.8 \%)$ \\
\hline Triglyceride (mmol/l) & $0.7 \%(0.2$ to $1.1 \%)$ & $-0.1 \%(-0.9$ to $0.7 \%)$ & $0.1 \%(-0.4$ to $0.5 \%)$ & $0.2 \%$ (-0.4 to $0.9 \%)$ \\
\hline Hbalc (\%) & - & $0.9 \%(-0.3$ to $2.2 \%)$ & $0.2 \%(-0.01$ to $0.6 \%)$ & $0.2 \%$ (-0.1 to $0.7 \%)$ \\
\hline $\begin{array}{l}\text { Duration of } \\
\text { diabetes (year) }\end{array}$ & - & $-5.1 \%(-7.5$ to $-2.7 \%)$ & $-1.7 \%(-3.1$ to $-0.3 \%)$ & $-0.5 \%(-1.2$ to $0.2 \%)$ \\
\hline \multicolumn{5}{|l|}{ Health related behaviors } \\
\hline Smoking & $-0.3 \%(-0.6$ to $0.04 \%)$ & $-0.2 \%(-0.5$ to $0.2 \%)$ & $-0.1 \%(-0.4$ to 0.1$)$ & $0.01 \%(-0.2$ to $0.3 \%)$ \\
\hline Alcohol & $-0.01 \%(-1.2$ to $1.0 \%)$ & $0.2 \%$ (-0.6 to $1.1 \%)$ & $-0.1 \%(-0.4$ to 0.2$)$ & $-0.3 \%$ (-0.9 to $0.5 \%)$ \\
\hline \multicolumn{5}{|l|}{ Acculturation factors } \\
\hline Country of birth & $2.1 \%(0.4$ to $3.7 \%)$ & $-0.5 \%(-2.5$ to $1.4 \%)$ & $0.1 \%(-0.9$ to $0.9 \%)$ & $-0.1 \%(-2.6$ to $1.1 \%)$ \\
\hline $\begin{array}{c}\text { Duration of } \\
\text { esidency (year) }\end{array}$ & $-1.9 \%(-4.0$ to $0.01 \%)$ & $-0.3 \%(-1.3$ to $0.8 \%)$ & $0.1 \%$ ( -0.4 to $0.6 \%)$ & $-0.2 \%(-1.1$ to $0.7 \%)$ \\
\hline \multicolumn{5}{|l|}{ jocioeconomic factors } \\
\hline Reading literacy & $0.4 \%(-0.4$ to $1.4 \%)$ & $-0.9 \%(-2.5$ to $0.7 \%)$ & $-0.2 \%(-0.7$ to $0.6 \%)$ & $-2.0 \%(-3.3$ to $-0.7 \%)$ \\
\hline Education & $-0.9 \%(-2.5$ to $1.0 \%)$ & $1.3 \%(-1.7$ to $4.3 \%)$ & $0.3 \%(-1.1$ to $1.9 \%)$ & $-1.1 \%(-4.0$ to $1.3 \%)$ \\
\hline Income & $-0.4 \%(-2.0$ to $0.9 \%)$ & $-2.2 \%(-4.7$ to $-0.2 \%)$ & $-1.4 \%(-3.0$ to $-0.2 \%)$ & $-0.6 \%$ ( -5.8 to $-0.1 \%)$ \\
\hline Housing type & $-0.5 \%(-1.3$ to $0.4 \%)$ & $-1.7 \%(-3.2$ to $-0.01 \%)$ & $-1.0 \%(-1.8$ to $-0.2 \%)$ & $-0.3 \%(-2.2$ to $0.7 \%)$ \\
\hline
\end{tabular}

$95 \% \mathrm{Cl}=95 \%$ confidence interval; $\mathrm{DR}=$ diabetic retinopathy; $\mathrm{VTDR}=$ vision-threatening diabetic retinopathy; $\mathrm{VI}=\mathrm{visual}$ impairment; $\mathrm{BMI}=$ body mass index; $\mathrm{SBP}=$ systolic blood pressure; $\mathrm{DBP}=$ diastolic blood pressure; $\mathrm{HDL}=$ high-density lipoprotein; $\mathrm{LDL}=$ low-density lipoprotein; $\mathrm{Hba} 1 \mathrm{C}=$ hemoglobin $\mathrm{A} 1 \mathrm{C}$. Bold font highlights statistical significance $(P<0.05)$. Smoking category: $0=$ current; $1=$ never; Alcohol category: $0=$ current; $1=$ never; Country of birth category: $0=$ foreignborn, 1 = Singapore-born; Reading literacy category" $0=$ adequate, $1=$ inadequate; Education category: $0=$ secondary education or higher, $1=$ formal education or lower; Income category: $0=$ lower than SGD $\$ 1,000,1=\mathrm{SGD} \$ 1,000$ or more; Housing type category: $0=5$-room flat or bigger, $1=4$-room flat or smaller.

characteristics ("explained" component). Age and socioeconomic factors (including reading literacy and income) had substantial contribution to the "explained" component.

To avoid over-adjustment, we also carried out supplementary analyses in Oaxaca decomposition model by controlling only those independent variables that were statistically significant in univariate regression analyses. First, we found that $53.9 \%(6.2 / 11.6)$ of the languagerelated disparity in prevalence of T2DM was attributed to "explained" component, and 46.1\% (5.4/11.6) to "unexplained" component, after controlling for the effect of age, gender, SBP, DBP, LDL, triglyceride, and country of birth. Second, $53.8 \%(2.7 / 5.1)$ of the language-related 
disparity in prevalence of DR (among those with T2DM) was attributed to "explained" component, and 46.2\% (2.3/5.1) to "unexplained" component, after controlling for the effect of age, gender, SBP, DBP, duration of diabetes, income and housing type. Third, 38.9\% (1.8/4.6) of the language-related disparity in prevalence of VTDR (among those with T2DM) was attributed to "explained" component, and $61.1 \%$ (2.8/4.6) to "unexplained" component, after controlling for the effect of age, duration of diabetes, income, and housing type. Finally, 46.9\% (9.0/ 19.2) of the language-related disparity in prevalence of VI (among those with T2DM) was attributed to "explained" component, and 53.1\% (10.2/19.2) to "unexplained" component, after controlling for the effect of age, reading literacy and income. None of the independent variables has significant influence on "unexplained" component (data not shown).

\section{Discussion}

This is the first population-based assessment of the association of English proficiency with T2DM and its key ocular complications. We demonstrated that there were significant language-related disparities between persons who were Tamil-speaking and English speaking: Tamilspeaking Indians were more likely to have T2DM than English-speaking Indians and, among those with diabetes, more likely to DR, VTDR and VI, complications which have immediate and substantial impacts on a patient's quality of life. Oaxaca decomposition method is an established tool for macroeconomic analysis and it provided us with a unique opportunity to identify factors explaining language-related disparities in Asian Indians living in a culturally diverse modern society [21]. For the prevalence of T2DM, it was age and systemic biological factors such as blood pressure and LDL that accounted for a substantial proportion of language-related disparity (Table 2). Surprisingly, socioeconomic and acculturation factors had limited contribution, suggesting that the influence of language on T2DM prevalence was not mediated by different levels of socioeconomic status. The implication is that reducing socioeconomic differences alone may be unlikely to remove language-related disparities in the prevalence of T2DM. These findings are critically important in developing policies and implementing linguistic-specific programs in the prevention of diabetes in Asia's multi-linguistic societies. Among those with diabetes, however, socioeconomic measure had significant contribution to the language-related disparities in prevalence of DR and VTDR. These findings reflect the complex influences of socioeconomic measures on the prevention and management of diabetes ocular complications.

The origins of the "unexplained" language-related disparities are multi-factorial, and as suggested by Marmot and others, the disparities could be broadly due to material deprivation and/or the lack of capability to control life and fully participate in the society (psychosocial disadvantage) [24]. We propose two possible explanations. First, English proficiency can be perceived as a proxy measure of acculturation and reflects immigrants' culture, social identity and political ideology [9], given that most of our participants are first or second generation of the immigrants from Indian subcontinent. In this regard, Asian Indians who speak English during interview are presumably the ones who are more adaptive to local culture and are more likely to be absorbed into the dominant society - a community that have an advantage in obtaining occupation opportunity, receiving social support, avoiding psychological stressors, and maintaining a healthy lifestyle. As a result, they may be less likely to have diabetes and its complications compared to Tamilspeaking Indians. Second, the "unexplained" disparities may be due to a lack of diabetes knowledge, medical information, patient-physician communication, and treatment adherence among those with poor language skill $[6-8,25]$. This view is supported by the findings from the United States that language ability can directly influence access to health care and has impact on health among the Hispanic populations [6-8]. Finally, our findings may be attributable to a "healthy migrant effect" (i.e., the new immigrants were generally healthier than the local residents), but our stratified analyses showed that this language-related disparity was also seen in Singapore born Indians. Further research is needed to evaluate and identify ways in which language barriers affect diabetes management and DR care, and to assess the cost effectiveness of language-specific health improvement programs and linguistic service among this heterogeneous population. Geographic condition is unlikely an explanation, given that the two communities were living in the same areas (totaling $42.6 \mathrm{sq}$ mile) and there were no transformational barriers across different districts [16].

The strengths of this study include its populationbased nature, objective measurement of diabetes and $\mathrm{DR}$, the use of Oaxaca decomposition analysis, and the ability to adjust for a wide range of potential risk factors. Several limitations should be highlighted as well. First, while interview language has been shown to be a better acculturation indicator than self-reported English proficiency [10], we could not exclude the possibility that there were some Indians who were proficient in English but chose/preferred to respond in Tamil, and consequently the observed associations may be biased towards the null. Nevertheless, we have opted to use the term "English proficiency" rather than "language preference"; although one is invariably linked with the other, the choice of Tamil language is more of an indicator of a lack of English language proficiency in this society. 
Second, our findings may be cultural specific, and not be generalizable to other Asian populations and other languages. Third, we did not collect data regarding diet, physical activity, and detailed use of medication, and the lack of these information may have led to an overestimation of language-related disparities. Finally, the effect of acculturation has been considered in our multivariate analysis by including migration status and length of residence in Singapore as covariates, but we did not consider the effects of other potential cultural factors (e.g., cultural traditions and behaviors).

\section{Conclusions}

In summary, in a society where English is the predominant working language, Tamil-speaking Indians are more likely to have T2DM and eye complications (DR and VI) than English-speaking Indians. The language-related disparities cannot be fully explained by biological risk factors and traditional socioeconomic measures. Language represents one of the key social determinants of health in many new multilingual societies around the world, including United States, Europe and Asia. While the pathways through which English language proficiency affect health remains to be determined, the immediate application of our study suggests that language service itself should be recognized as a critical component of health equality and health care programs.

\section{Competing interests}

The authors declare that they have no competing interests.

\section{Authors' contributions \\ Y.Z. conducted the statistical analysis and wrote the manuscript; E.L.L., directed the implementation of the study and helped reviewed the manuscript; P.C. helped conduct statistical analysis and edited the manuscript; A.R.A. helped designed the analytic strategy; J.D. contributed to discussion and helped review the manuscript; J.J.W. helped supervise the field activities and edited the manuscript; P.M. helped conduct the literature review and edited the manuscript; E.T. helped set up and supervise the project and reviewed the manuscript; T.Y.W. designed and supervised the project, contributed to discussion, and reviewed/edited the manuscript. All authors read and approved the final manuscript.}

\section{Acknowledgement}

This study was funded by Biomedical Research Council (BMRC), 08/1/35/19/ 550 \& National Medical Research Council (NMRC), STaR/0003/2008, Singapore. The authors thank Mireille Moffitt (Centre for Vision Research, Department of Ophthalmology, Westmead Millennium Institute, University of Sydney, Australia) for assistance in the grading of diabetic retinopathy.

\footnotetext{
Author details

${ }^{1}$ Singapore Eye Research Institute, Singapore National Eye Centre, 11 Third Hospital Ave, \#05-00, Singapore 168751, Singapore. ${ }^{2}$ State Key Laboratory of Ophthalmology, Zhongshan Ophthalmic Center, Sun Yat-sen University, \#54 Xianlie Road, Guangzhou 510060, China. ${ }^{3}$ Centre for Eye Research Australia, University of Melbourne, the Royal Victorian Eye and Ear Hospital, 32 Gisborne Street, East Melbourne, VIC 3002, Australia. ${ }^{4}$ University of Malaya Eye Research Centre, Faculty of Medicine, University of Malaya, Kuala Lumpur, Malaysia. ${ }^{5}$ Department of Ophthalmology, Faculty of Medicine, University of Malaya, Kuala Lumpur 50603, Malaysia. ${ }^{6}$ Centre for Vision Research, Department of Ophthalmology and Westmead Millennium Institute, University of Sydney, Sydney, NSW 2145, Australia. ${ }^{7}$ Department of Ophthalmology, Yong Loo Lin School of Medicine, National University of
}

Singapore, 5 Lower Kent Ridge Road, Singapore 119074, Singapore. ${ }^{8}$ Department of Medicine, Yong Loo Lin School of Medicine, National University of Singapore, 5 Lower Kent Ridge Road, Singapore 119074, Singapore.

Received: 6 March 2012 Accepted: 10 September 2012 Published: 13 September 2012

\section{References}

1. Cheung N, Mitchell P: Wong TY: Diabetic retinopathy. Lancet 2010, 376:124-136.

2. Lamoureux EL, Wong TY: Diabetic retinopathy in 2011: further insights from new epidemiological studies and clinical trials. Diabetes Care 2011, 34:1066-1067.

3. Whiting D, Unwin N, Roglic G: Diabetes: equity and social determinants. In Equity, social determinants and public health programmes. Edited by Blas $\mathrm{E}$, Kurup AS; 2010. http://whqlibdoc.who.int/publications/2010/ 9789241563970_eng.pdf) (Accessed on 16 August, 2011).

4. Flores G: Language barriers to health care in the United States. N Engl J Med 2006, 355:229-231.

5. Woloshin S, Bickell NA, Schwartz LM, Gany F, Welch HG: Language barriers in medicine in the United States. JAMA 1995, 273:724-728.

6. DuBard CA, Gizlice Z: Language spoken and differences in health status, access to care, and receipt of preventive services among US Hispanics. Am J Public Health 2008, 98:2021-2028.

7. Pearson WS, Ahluwalia IB, Ford ES, Mokdad AH: Language preference as a predictor of access to and use of healthcare services among Hispanics in the United States. Ethn Dis 2008, 18:93-97.

8. Stein JA, Fox SA: Language preference as an indicator of mammography use among Hispanic women. J Natl Cancer Inst 1990, 82:1715-1716.

9. Lara M, Gamboa C, Kahramanian MI, Morales LS, Bautista DE: Acculturation and Latino health in the United States: a review of the literature and its sociopolitical context. Annu Rev Public Health 2005, 26:367-397.

10. Coren JS, Filipetto FA, Weiss LB: Eliminating barriers for patients with limited English proficiency. J Am Osteopath Assoc 2009, 109:634-640.

11. Lee S, Nguyen HA, Tsui J: Interview language: a proxy measure for acculturation among Asian Americans in a population-based survey. J Immigr Minor Health 2011, 13:244-252.

12. Ayers JW: Measuring English proficiency and language preference: are self-reports valid? Am J Public Health 2010, 100:1364-1366.

13. Lee WR: The changing demography of diabetes mellitus in Singapore. Diabetes Res Clin Pract 2000, 50(Suppl 2):S35-39.

14. Chiang PP, Lamoureux EL, Cheung CY, Sabanayagam C, Wong W, Tai ES, Lee J, Wong TY: Racial differences in the prevalence of diabetes but not diabetic retinopathy in a multi-ethnic Asian population. Invest Ophthalmol Vis Sci 2011, 52:7586-7592.

15. Singapore Department of statistics: Singapore census of population 2010: Statistical release 1: demographic characteristics, education, language and religion; 2010. http://www.singstat.gov.sg/pubn/popn/c2010sr1/cop2010sr1. pdf) (Accessed August 16, 2011).

16. Lavanya R, Jeganathan VS, Zheng Y, Raju P, Cheung N, Tai ES, Wang JJ, Lamoureux E, Mitchell P, Young TL, Cajucom-Uy H, Foster PJ, Aung T, Saw SM, Wong TY: Methodology of the Singapore Indian Chinese Cohort (SICC) eye study: quantifying ethnic variations in the epidemiology of eye diseases in Asians. Ophthalmic Epidemiol 2009, 16:325-336.

17. Zheng Y, Lavanya R, Wu R, Wong WL, Wang JJ, Mitchell P, Cheung N, Cajucom-Uy H, Lamoureux E, Aung T, Saw SM, Wong TY: Prevalence and causes of visual impairment and blindness in an urban Indian population: The Singapore Indian Eye Study. Ophthalmology 2011, 118:1798-1804.

18. Wong TY, Cheung N, Tay WT, Wang JJ, Aung T, Saw SM, Lim SC, Tai ES, Mitchell P: Prevalence and risk factors for diabetic retinopathy: the Singapore Malay Eye Study. Ophthalmology 2008, 115:1869-1875.

19. Wong TY, Klein R, Islam FM, Cotch MF, Folsom AR, Klein BE, Sharrett AR, Shea S: Diabetic retinopathy in a multi-ethnic cohort in the United States. Am J Ophthalmol 2006, 141:446-455.

20. Zheng Y, Lamoureux EL, Chiang PP, Cheng CY, Anuar AR, Saw SM, Aung T, Wong TY: Literacy is an Independent Risk Factor for Vision Impairment and Poor Visual Functioning. Invest Ophthalmol Vis Sci 2011, 52:7634-7639.

21. Jann B: The Blinder-Oaxaca decomposition for linear regression models. Stata J 2008, 8:453-479. 
22. Neumark D: Employers' Discriminatory Behavior and the Estimation of Wage Discrimination. J Hum Resour 1988, 23:279-295.

23. Fairlie RW: An extension of the Blinder-Oaxaca decomposition technique to logit and probit models. J Econ Soc Meas 2005, 30:305-316.

24. Marmot MG: Status syndrome: a challenge to medicine. JAMA 2006, 295:1304-1307.

25. Hsu WC, Cheung S, Ong E, Wong K, Lin S, Leon K, Weinger K, King GL: Identification of linguistic barriers to diabetes knowledge and glycemic control in Chinese Americans with diabetes. Diabetes Care 2006, 29:415-416.

doi:10.1186/1471-2458-12-781

Cite this article as: Zheng et al:: Language barrier and its relationship to diabetes and diabetic retinopathy. BMC Public Health 2012 12:781.

\section{Submit your next manuscript to BioMed Central and take full advantage of:}

- Convenient online submission

- Thorough peer review

- No space constraints or color figure charges

- Immediate publication on acceptance

- Inclusion in PubMed, CAS, Scopus and Google Scholar

- Research which is freely available for redistribution 